\section{BMJ Open} Ophthalmology

\title{
Evaluation of effect of bevacizumab on central subfield macular thickness in the injected and contralateral (untreated) eye of patients with bilateral diabetic macular oedema
}

\author{
Anadi Khatri, ${ }^{1}$ Pratap Karki, ${ }^{2}$ Sagun Narayan Joshi, ${ }^{2}$ Ranju Kharel Sitaula ${ }^{2}$
}

To cite: Khatri A, Karki P, Joshi SN, et al. Evaluation of effect of bevacizumab on central subfield macular thickness in the injected and contralateral (untreated) eye of patients with bilateral diabetic macular oedema. BMJ Open Ophthalmology 2017;2:e000102. doi:10.1136/ bmjophth-2017-000102

Received 8 August 2017 Revised 14 November 2017 Accepted 21 November 2017

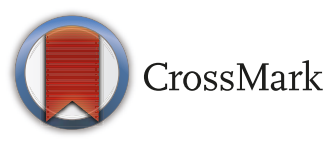

${ }^{1}$ Department of Ophthalmology, Birat Eye Hospital, Biratnagar, Nepal

${ }^{2}$ Department of Ophthalmology, B P Koirala Lions Centre for Ophthalmic Studies, Institute of Medicine, Tribhuvan University, Kathmandu, Nepal

Correspondence to Dr Anadi Khatri, Department of Ophthalmology , Birat Eye Hospital, Biratnagar, Nepal ; anadikc@gmail.com

\section{ABSTRACT}

Purpose Antivascular endothelial growth factor (anti-VEGFs) - bevacizumab is routinely utilised for the treatment of diabetic macular oedema (DME). We plan to evaluate the impact of bevacizumab on the central subfield macular thickness (CSMT) of the treated and untreated eye.

Methods A sequential group of patients with bilateral DME who were treated with unilateral bevacizumab injection were assessed preinjection and postinjection by Spectral Domain-Optical Coherence Tomography (SD-OCT) by CSMT.

Results Thirty-one patients, 20 male and 11 female, were evaluated. Seven patients had type 1 diabetes mellitus and 24 had type 2 diabetes mellitus. In regard to the duration of disease, 23 patients had diabetes for more than 10 years, seven patients had the condition for 5-10 years and one patient for more than 5 years. Mean age of the patients was 60.48 years $(\mathrm{SD} \pm 7.13$ ) with the range of $46-72$ years. Mean follow-up was 28 days (range 26-35 days). The eyes which received intravitreal injection had median CSMT of $473.2 \mu \mathrm{m}$ (range 321-566 $\mu \mathrm{m}$ ). The CSMT of the contralateral eye had median of $347.6 \mu \mathrm{m}$ (range $357-437 \mu \mathrm{m}$ ). A median reduction of $-132 \mu \mathrm{m}$ (range $93-156 \mu \mathrm{m}$ ) could be observed in the treated eye and $-18 \mu \mathrm{m}$ (range 15-22) in the untreated eye after treatment. Our study also found that eyes with greater CSMT, when injected with bevacizumab, produced higher responses in the contralateral eye $\left(R^{2} 0.538, P<0.05\right)$.

Conclusions Patients with bilateral DME treated with bevacizumab in one eye produced a bilateral response. Eyes with greater CSMT due to DME elicited higher levels of response in the untreated eye.

\section{INTRODUCTION}

Ocular pathologies involving macula are particularly destructive and irreversible to central visual acuity. Among myriad of various conditions, diabetic macular oedema (DME) is one of the leading cause of severe visual loss. ${ }^{1}$ Many studies have established the essential role of vascular endothelial growth factor (VEGF) in DME through its effect on angiogenesis. ${ }^{2}$ In people, VEGF levels have been associated with the initiation and severity of

\section{Key messages}

Various studies have already shown that antivascular endothelial growth factor (anti-VEGF) agents may produce a therapeutic effect in the untreated eye as well. Our study adds further strength to that finding.

After searching through a vast number of articles, our study adds an interesting finding - which to our knowledge after has not been stated before. Our study found that eyes with higher CSMT when treated produced a greater effect on the untreated eye. We propose that eyes with higher CSMT may have more disrupted blood-retinal barrier, hence enhancing escape of the drug but this further needs to be verified by quantifying VEGF and anti-VEGF levels in such eyes.

- Precaution must be taken in patients receiving antiVEGFs if they have any pathology like vitreomacular traction, tractional bands or proliferative vitreoretinopathy in the other eye. The severity of pathology in such eyes may worsen due to the contralateral effect of anti-VEGF.

neovascularisation and vascular spillage. ${ }^{3}$ VEGF, in this manner, is also the most noticeable molecule actuating neovascularisation, and therefore, medications hindering VEGF bioactivity have been generally utilised as the new world view to treat DME.

Bevacizumab has been long listed as one of the several options to treat choroidal neovascularisation by intravitreal injection (ITV) in many countries. It is a strong inhibitor of all VEGF-A isoforms. ${ }^{4}$ First to be reported by Rosenfeld et $a l^{5}$ many further studies and researches have established the benefits and effectiveness of this drug. ${ }^{6}$ Bevacizumab can sometimes be associated with serious ocular adverse side effects but over the years, multiple studies have shown that bevacizumab can be administered intravitreally and are well tolerated by human eyes. ${ }^{7-9}$ 
VEGF molecules are found in the retina under physiological conditions, and recent studies have highlighted its important role in maintaining vascular tone and permeability. ${ }^{10}$ The plasma levels of VEGF in patients were observed to be essentially diminished after the intravitreal infusion of bevacizumab. ${ }^{11}$ This finding proposed that the body clears anti-VEGF after intravitreal administration. As the drug reaches systemic circulation, this prompts the question of whether there is an impact on the contralateral eye. There are few results from investigations ${ }^{11}$ with respect to the pharmacokinetics and appropriation of these in human eyes. The objective of this study was to evaluate the impact of ITV bevacizumab in DME in the injected and in the untreated eye.

\section{METHODOLOGY}

\section{Prospective study}

The research protocol was approved by the ethics committee and adhered to the tenets of the Declaration of Helsinki. Thirty-one patients with bilateral DME were recruited after standard ophthalmological examination. The diagnosis of DME was based on Optical Coherence Tomography OCT (Heidelberg Spectralis). At the point when a patient was considered to have a clinical indication for ITV bevacizumab treatment, they were assessed for qualification for this investigation. The exclusion criteria included patients with uncontrolled hypertension, a history of myocardial infarction or cerebral vascular accident and media opacities. Patients with history of treatment with laser, retinal surgery and periocular/intraocular injection of anti-VEGF or steroids were not included in the study. Similarly, cases with epiretinal membrane and vitreomacular traction (VMT) were also excluded.

The preparation of bevacizumab was done using a standard aseptic procedure to partition the doses from the phial $(100 \mathrm{mg} / 4 \mathrm{~mL})$ into $1 \mathrm{~mL}$ tuberculin syringes containing $0.05 \mathrm{~mL}$ of bevacizumab. The drug was injected using a standard aseptic convention, including the utilisation of a topical analgesic, povidone-iodine scrubbing and a sterile speculum. Bevacizumab was injected into the vitreous through the pars plana $3.5-4 \mathrm{~mm}$ posterior to the limbus using a sterile 30 -gauge needle. Recorded outcome measurements include the best-corrected visual acuity assessment with the Early Treatment Diabetic Retinopathy Study chart and the central subfield macular thickness (CSMT) measurement of the treated and untreated eye before and at 4 weeks after the injections.

\section{Statistical analysis}

SPSS software, V.19.0 was used for statistical analysis. Linear regression analysis and Mann-Whitney test were applied to see the correlation.

\section{RESULTS}

\section{Subject population}

Thirty-four patients were enrolled but three of the patient were either lost or excluded from the study.
Table 1 Baseline demographics and ocular characteristics of patients with diabetes macular oedema including preoutcomes and post-outcomes after treatment with antivascular endothelial growth factor therapy

\begin{tabular}{|c|c|}
\hline General characteristics & $\begin{array}{l}\text { Diabetic macular oedema } \\
\text { ( } n=31 \text { eyes from } 31 \text { patients) }\end{array}$ \\
\hline \multicolumn{2}{|l|}{ Age } \\
\hline Median (min, max) & $61.0(46,72)$ \\
\hline \multicolumn{2}{|l|}{ Gender } \\
\hline Male & $20(64.5 \%)$ \\
\hline Female & $11(35.5 \%)$ \\
\hline \multicolumn{2}{|l|}{ Diabetes } \\
\hline Type 1 & $7(22.6 \%)$ \\
\hline Type 2 & $24(77.4 \%)$ \\
\hline \multicolumn{2}{|l|}{ Retinopathy status } \\
\hline \multicolumn{2}{|l|}{ Treated eye } \\
\hline NPDR & $29(93.5 \%)$ \\
\hline PDR & $2(6.5 \%)$ \\
\hline \multicolumn{2}{|l|}{ Untreated eye } \\
\hline NPDR & $31(100 \%)$ \\
\hline PDR & $0(0 \%)$ \\
\hline \multicolumn{2}{|l|}{ Duration of diabetes } \\
\hline More than 10 years & $23(74.2 \%)$ \\
\hline 5-10years & $7(22.6 \%)$ \\
\hline Less than 5 years & $1(3.2 \%)$ \\
\hline \multicolumn{2}{|c|}{ Baseline CSMT of eyes (median) ( $\mu \mathrm{m} / \mathrm{range})$} \\
\hline Treated & $473 \mu \mathrm{m}$ (range $321-566 \mu \mathrm{m})$ \\
\hline Untreated & $347 \mu \mathrm{m}$ (range $357-437 \mu \mathrm{m})$ \\
\hline \multicolumn{2}{|c|}{ Post-treatment of CSMT of eyes (median) ( $\mu \mathrm{m} / \mathrm{range})$} \\
\hline Treated & $301 \mu \mathrm{m}$ (range 286-324 $\mu \mathrm{m})$ \\
\hline Untreated & $308 \mu \mathrm{m}$ (range 259-317 $\mu \mathrm{m})$ \\
\hline \multicolumn{2}{|c|}{ Decrease in CSMT of eyes $(\mu \mathrm{m})$ (median) $(\mu \mathrm{m} / \mathrm{range})$} \\
\hline Treated & $-132 \mu \mathrm{m}$ (range 93-156 $\mu \mathrm{m})$ \\
\hline Untreated & $-18 \mu \mathrm{m}$ (range $15-22 \mu \mathrm{m})$ \\
\hline
\end{tabular}

CSMT, central subfield macular thickness; NPDR, non-proliferative diabetic retinopathy; PDR, proliferative diabetic retinopathy.

Subjects absent at any one of the three visits were also excluded from the study. Proper data were obtained from 31 subjects (20 men and 11 women) and were included in the analysis (table 1$)$. The mean age $( \pm \mathrm{SD})$ was 60.48 ( $\mathrm{SD} \pm 7.13)$ (range 46-72 years). Seven patients $(22.5 \%)$ had type 1 diabetes and $24(87.5 \%)$ had type 2 diabetes (table 1). Twenty-three of the patients had diabetes for 10 years, seven for 5-10 years and one for less than 5 years (table 1$)$. Twenty-nine $(93.7 \%)$ eyes that were treated had non-proliferative diabetic retinopathy (NPDR) and two (6.3\%) had proliferative retinopathy, while all the observed eyes had NPDR (table 1).

The baseline CSMT of the eyes which received intravitreal injection had a median value of $473 \mu \mathrm{m}$ (range 


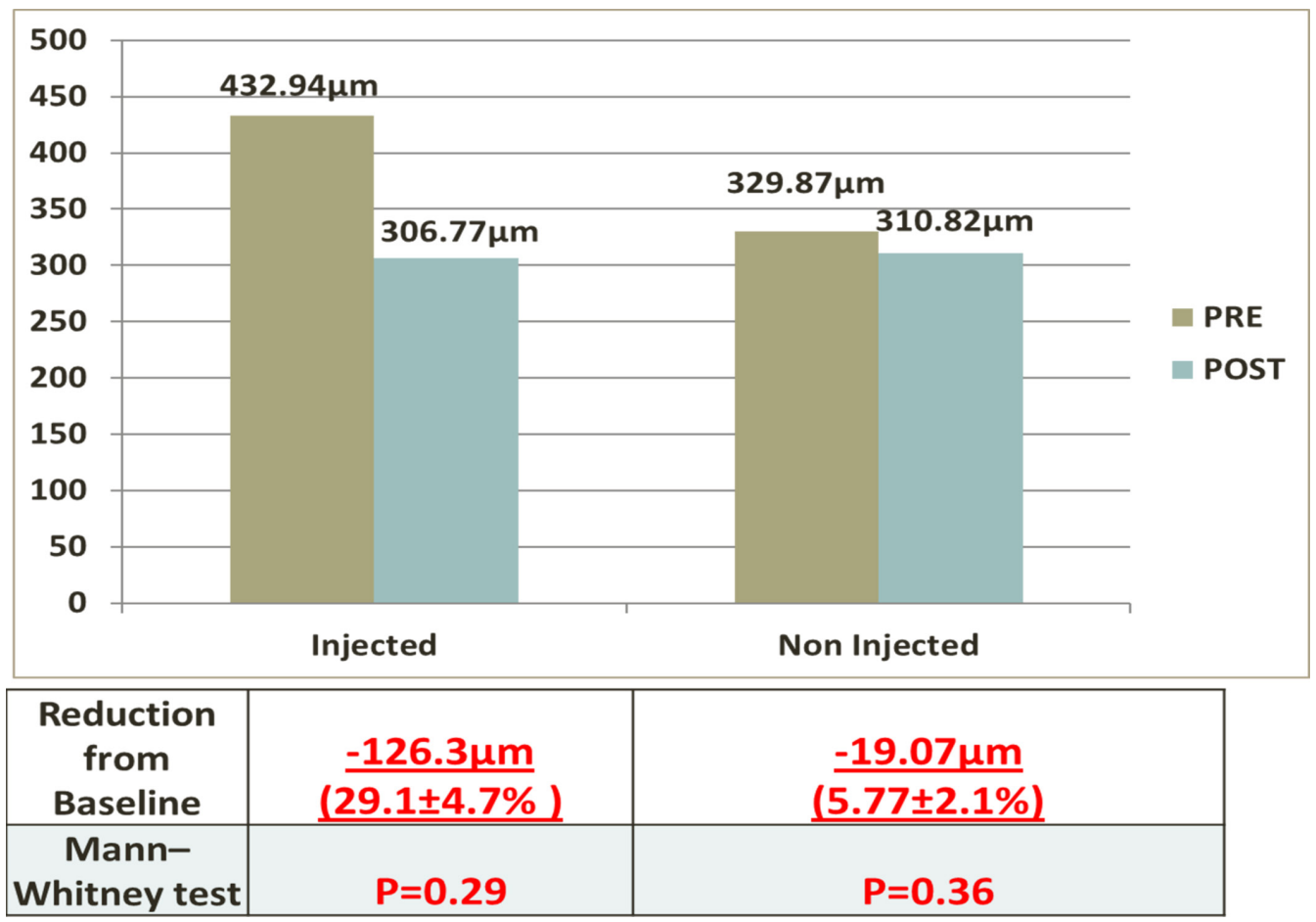

Figure 1 A comparison of the changes in the central subfield macular thickness (CSMT) in treated and untreated eyes of the same patients, before (baseline) and at 4 weeks after the intravitreal bevacizumab. Note that a statistically significant decrease in the CSMT.

$321-566 \mu \mathrm{m})$. The CSMT of the untreated eye had median of $347 \mu \mathrm{m}$ (range $357-437 \mu \mathrm{m}$ ).

Four weeks after the injection, CSMT of both the treated and the untreated eye was measured. A median reduction of $-132 \mu \mathrm{m}$ (range 93-156 $\mu \mathrm{m}$ ) could be observed in the treated eye and --18 $\mu \mathrm{m}$ (range 15-22) in the untreated eye (table 1). These changes in CSMT in the treated and the untreated eyes were found to be statistically significant when analysed using Mann-Whitney test $(\mathrm{P}=0.29$ and $\mathrm{P}=0.36$, respectively) (figure 1$)$. We observed that approximately $15 \%$ of the therapeutic effect could be seen in untreated eyes. Using linear regression and curve estimator, both supported the finding that eyes with greater CSMT which were treated with bevacizumab produced higher levels of contralateral responses $\left(\mathrm{R}^{2}\right.$ $0.538, \mathrm{P}<0.001$ ) (figure 2). We also analysed our data to verify if this finding was confounded due to chances of the contralateral eyes also having higher CSMT, hence showing greater reduction. But with linear regression analysis, such relation could not be established and was statistically insignificant $\left(\mathrm{R}^{2}=0.014, \mathrm{P}=0.54\right)$ (figure 3).

\section{DISCUSSION}

This study demonstrates the presence of the contralateral effect of bevacizumab injections. Fellow eyes with DME which had never received any treatment in the past produced decrease in the CSMT following administration of this drug in the other eye.

It has been widely accepted that anti-VEGF drugs can enter the systemic circulation even when administered via intravitreal route in humans. Various studies have further added value to this finding by demonstrating reduction in serum of VEGF levels after intravitreal bevacizumab injections, various retinal pathologies such as retinopathy of prematurity, ${ }^{12}$ wet age-related macular degeneration ${ }^{13}$ and in DME. ${ }^{14}$

Systemic 'leakage' of anti-VEGF compounds following intravitreal injections can be taken both as an advantage and disadvantage. It can provide a hidden advantage to the contralateral eye as shown in our study. But further investigations will be required to establish if this may also produce unexpected treatment effects in eyes having other retinal pathologies, which may produce harm. ${ }^{71516}$

However, various investigations have also provided conflicting information in this regard. Meyer et $a l^{17}$ reported imperceptible levels of unbound bevacizumab in the aqueous humour of the non-injected eye. The authors yield that anti-VEGF action of bevacizumab may occur without being identified in the aqueous and possibility that systemic alterations in VEGF level may affect DME.

Velez-Mentoya $e \mathrm{al}^{18}$ also failed to demonstrate a contralateral eye effect in a prospective study of 23 patients with bilateral DME who received unilateral intravitreal bevacizumab.

On the other hand, Bakbak et $a l^{19}$ recently reported of significant contralateral eye effect for bevacizumab in 55 patients with bilateral DME.

From our study, we also found that greater the CSMT, the higher the response in the contralateral eye of bevacizumab. We are unaware of any previous studies that have evaluated this finding. We analysed our data to verify if this 
PRE
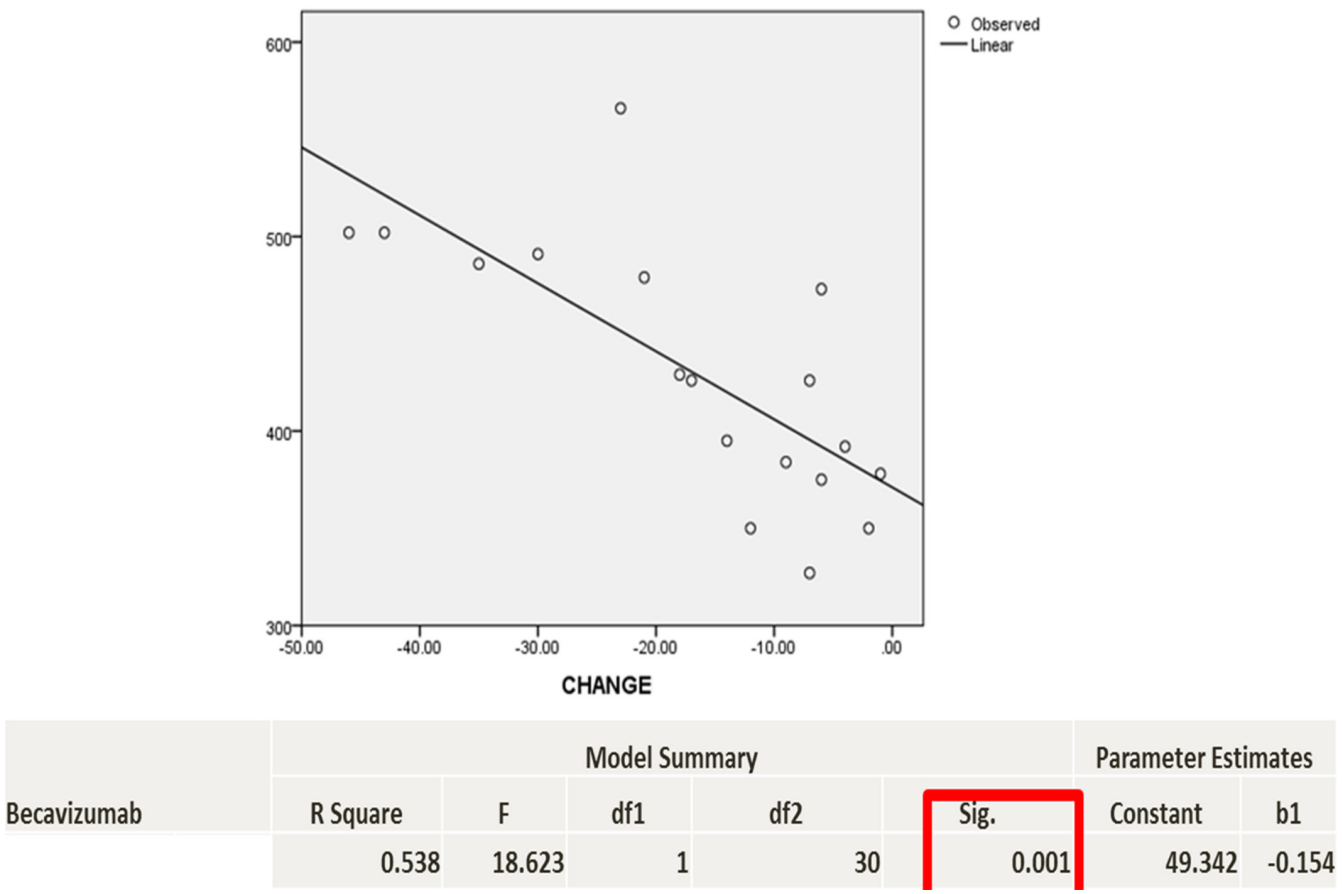

Figure 2 CSMT of the injected eye and magnitude of effect on contralateral eye. Eyes with higher CSMT when treated show greater response in the untreated eye using linear regression estimator. Change, change in the CSMT of the untreated eye; CSMT, central subfield macular thickness; PRE, pretreatment CSMT.

higher response was the result of the contralateral eyes also having greater macular thickness. But with further statistical analysis using linear regression analysis and estimator, such relation could not be established and was statistically insignificant $\left(\mathrm{R}^{2}=0.014, \mathrm{P}=0.54\right)$ (figure 3$)$. It has been suggested that the blood-retina barrier may

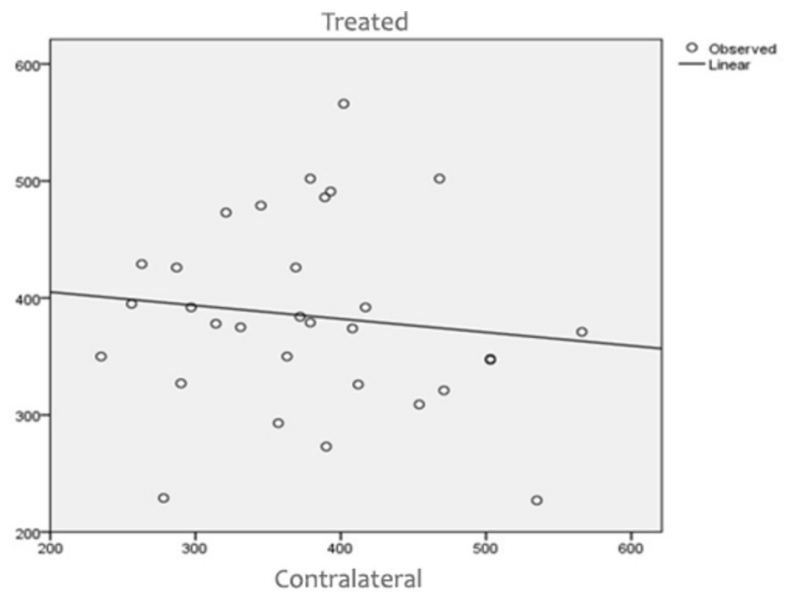

Dependent Variable: Treated

\begin{tabular}{|c|c|c|c|c|c|c|c|}
\hline \multirow[b]{2}{*}{ Equation } & \multicolumn{5}{|c|}{ Model Summary } & \multicolumn{2}{|c|}{ Parameter Estimates } \\
\hline & R Square & $\mathrm{F}$ & df1 & $d f 2$ & Sig. & Constant & b1 \\
\hline Linear & .014 & .417 & 1 & 30 & .524 & 428.027 & -.115 \\
\hline
\end{tabular}

Figure 3 Comparison of central subfield macular thickness (CSMT) of both eyes before treatment (baseline). Higher CSMT or lower CSMT in one eye did not correspond to similar finding in the other eye when the data were analysed with linear regression estimator. require multiple doses in establishing a long-term effect of anti-VEGF compounds before maximal clinical response can be seen in DME. ${ }^{20}$ The hypothetical assumption is that eyes with greater oedema usually have more extensive blood-retinal barrier dysfunction and hence cause more molecules to escape to systemic circulation. However, further research is required to add value to this thought.

We recommend treating cases of bilateral DME only after evaluation of the fellow eye. Some of the benefits in treating one eye instead of both initially are reduced pain/discomfort, risk for ocular complication and in our part of the world, cost. But a precaution must be taken if the contralateral eye is pathological with VMT, tractional bands or proliferative vitreoretinopathy. The contralateral effect may worsen the macular oedema in such cases, but this relation still needs to be established and adds a new ground for further research.

Acknowledgements We would like to thank Suresh Raj Sharma, senior technical staff, for performing the OCT on our patients.

Contributors AK planned the study and was involved in patient enrolment, history taking, clinical examination, data collection and analysis and drafting of the manuscript. PK and SNJ were directly involved in the patient management, administration of intravitreal drugs and monitoring the treatment outcome. RKS was involved in interpreting the OCT findings and in drafting and critical review of the manuscript.

Competing interests None declared.

Patient consent Obtained.

Ethics approval Institutioanl Review Board, IOM.

Provenance and peer review Not commissioned; externally peer reviewed. 
Open Access This is an Open Access article distributed in accordance with the Creative Commons Attribution Non Commercial (CC BY-NC 4.0) license, which permits others to distribute, remix, adapt, build upon this work non-commercially, and license their derivative works on different terms, provided the original work is properly cited and the use is non-commercial. See: http://creativecommons.org/ licenses/by-nc/4.0/

(c) Article author(s) (or their employer(s) unless otherwise stated in the text of the article) 2017. All rights reserved. No commercial use is permitted unless otherwise expressly granted.

\section{REFERENCES}

1. Kulkarni AD, Kuppermann BD. Wet age-related macular degeneration. Adv Drug Deliv Rev 2005;57:1994-2009.

2. Shams N, lanchulev T. Role of vascular endothelial growth factor in ocular angiogenesis. Ophthalmol Clin North Am 2006;19:335-44.

3. Aiello LP, Avery RL, Arrigg PG, et al. Vascular endothelial growth factor in ocular fluid of patients with diabetic retinopathy and other retinal disorders. N Engl J Med 1994;331:1480-7.

4. Moshfeghi AA, Rosenfeld PJ, Puliafito CA, et al. Systemic bevacizumab (avastin) therapy for neovascular age-related macular degeneration: twenty-four-week results of an uncontrolled openlabel clinical study. Ophthalmology 2006;113:e1-12.

5. Michels S, Rosenfeld PJ, Puliafito CA, et al. Systemic bevacizumab (avastin) therapy for neovascular age-related macular degeneration twelve-week results of an uncontrolled open-label clinical study. Ophthalmology 2005;112:1035-47.

6. Schouten JS, La Heij EC, Webers CA, et al. A systematic review on the effect of bevacizumab in exudative age-related macular degeneration. Graefes Arch Clin Exp Ophthalmol 2009;247:1-11.

7. Avery RL, Pearlman J, Pieramici DJ, et al. Intravitreal bevacizumab (avastin) in the treatment of proliferative diabetic retinopathy. Ophthalmology 2006;113:1695-705.

8. Fung $A E$, Rosenfeld PJ, Reichel E. The international intravitreal bevacizumab safety survey: using the internet to assess drug safety worldwide. Br J Ophthalmol 2006;90:1344-9.

9. Rich RM, Rosenfeld PJ, Puliafito CA, et al. Short-term safety and efficacy of intravitreal bevacizumab (avastin) for neovascular agerelated macular degeneration. Retina 2006;26:495-511.
10. Brylla E, Tscheudschilsuren G, Santos AN, et al. Differences between retinal and choroidal microvascular endothelial cells (MVECs) under normal and hypoxic conditions. Exp Eye Res 2003;77:527-35.

11. Zehetner C, Kirchmair R, Huber S, et al. Plasma levels of vascular endothelial growth factor before and after intravitreal injection of bevacizumab, ranibizumab and pegaptanib in patients with agerelated macular degeneration, and in patients with diabetic macular oedema. Br J Ophthalmol 2013;97:454-9.

12. Matsuyama K, Ogata N, Matsuoka M, et al. Plasma levels of vascular endothelial growth factor and pigment epithelium-derived factor before and after intravitreal injection of bevacizumab. $\mathrm{Br} J$ Ophthalmol 2010;94:1215-8.

13. Sato T, Wada K, Arahori H, et al. Serum concentrations of bevacizumab (avastin) and vascular endothelial growth factor in infants with retinopathy of prematurity. Am J Ophthalmol 2012;153:327-33.

14. Chakravarthy U, Harding SP, Rogers CA, et al. Ranibizumab versus bevacizumab to treat neovascular age-related macular degeneration: one-year findings from the IVAN randomized trial. Ophthalmology 2012;119:1399-411.

15. Acharya NR, Sittivarakul W, Qian Y, et al. Bilateral effect of unilateral ranibizumab in patients with uveitis-related macular edema. Retina 2011;31:1871-6.

16. Al-Dhibi $\mathrm{H}, \mathrm{Khan} \mathrm{AO}$. Bilateral response following unilateral intravitreal bevacizumab injection in a child with uveitic cystoid macular edema. J AAPOS 2009;13:400-2.

17. Meyer $\mathrm{CH}$, Krohne TU, Holz FG. Concentrations of unbound bevacizumab in the aqueous of untreated fellow eyes after a single intravitreal injection in humans. Acta Ophthalmol 2012;90:68-70.

18. Velez-Montoya R, Fromow-Guerra J, Burgos O, et al. The effect of unilateral intravitreal bevacizumab (avastin), in the treatment of diffuse bilateral diabetic macular edema: a pilot study. Retina 2009;29:20-6.

19. Bakbak B, Ozturk BT, Gonul S, et al. Comparison of the effect of unilateral intravitreal bevacizumab and ranibizumab injection on diabetic macular edema of the fellow eye. J Ocul Pharmacol Ther 2013;29:728-32.

20. Kook D, Wolf A, Kreutzer T, et al. Long-term effect of intravitreal bevacizumab (avastin) in patients with chronic diffuse diabetic macular edema. Retina 2008;28:1053-60. 